Grzegorz Graniak, Bożena Wlizło-Skowronek, Paweł Rutyna Marcin Niemcewicz, Agata Bielawska-Drózd, Aleksandra Nakonieczna

Dorota Żakowska, Tomasz Mirski and Patrycja Głowacka

\title{
1. ORGANISATION OF THE BIOLOGICAL SAMPLING PROCESS
}

\subsection{Introduction}

A well-planned and coordinated biological sampling process during the CBRN incident is extremely important for further operations, both military and civil. For this reason, the collect of different types of samples must be carried out in accordance with a detailed plan, to provide as much information as possible. Further procedures in the detailed diagnosis and analysis of the collected material is carried out by specialized laboratories (mobile field labs and stationary reference laboratories).

The process of planning and conducting sampling activities involves thorough coordination and careful execution. Teams performing sampling activities must be well trained and have the specialized equipment to perform the sampling process correctly. CBRN command officers must plan and coordinate the entire sampling process to ensure the safety and high quality of the samples. Task include command and control, sampling, packing and transport, analysis and interpretation of the data within the chain of custody.

\subsection{Composition of survey, sampling and decontamination tasks}

A CBRN investigation is the directed effort to determine the nature and degree of CBRN hazards in the area of contamination, and to outline the boundaries of the hazard area. Environmental sampling is the first important and critical step in determining the nature and scope of the threat from a biological agents. Since sampling is a key issue for biological detection, the way a sample is taken and how it is handled will important affect the result of the analysis. In this reason well-developed and detailed planning is essential element in the sampling process. 


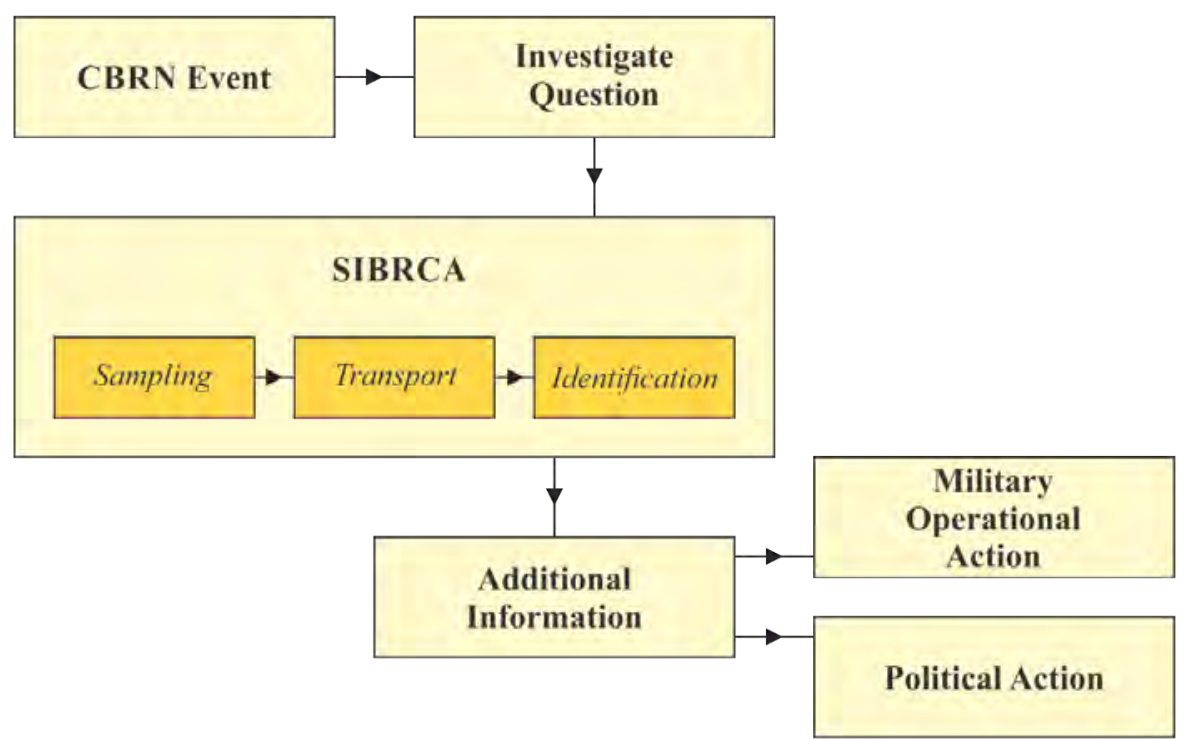

Figure 1. The place of SIBCRA missions in the CBRN event-response chain

All substantial procedures concerning sample collection and processing should be based on documented Standing Operating Procedures (SOP). The SOPs should describe necessary equipment/instrumentation, proper equipment use, and step-by-step procedures in each operational phase (immediate, urgent, late).

Anextremelyimportantstepduring the sampling processisthe decontamination of personnel, equipment and vehicles involved in the SIBCRA mission.

The aim of decontamination is to neutralize or eliminate contamination completely or at least to the extent that the operation can be continued without individual protection. The levels of decontamination include: immediate decontamination (minimize casualties and limit spread of contamination), operational decontamination (done by the sampling personnel or specific decontamination teams), clearance decontamination (conducted by specialized CBRN units). All elements/units, including sampling issue, should be capable of conducting their own operational decontamination.

\subsection{Essential equipment for survey, sampling and decontamination personnel}

Sampling Team (SIBCRA team) are responsible for the collecting samples, preliminary identification (in situ analysis via portable instruments and immunochemical hand-held kits), packaging and transport samples to the 
laboratory (field deployable lab or reference lab). The collection of specimens from humans and small animals as a result of any suspected contamination, requires the augmentation of these teams by additional technician specialists.

The Sampling Team must operate according to established and verified operational procedures. Uniformity, safety, and accountability in sampling procedures must be ensured. The procedures for transport and handling of CBR samples and specimens are covered by national directives. Proper chain of custody has to be ensured and documented to establish forensic evidence, so that unambiguous identification by certified laboratories is achievable. SOPs should be exercised regularly as part of the basic training.

The size of a typical sampling team (Specialist Sampling Team) is four to five personnel. If it required the SIBCRA team size will have to be increased to take into account the additional duties. The tasks assigned to the people on the Specialist Sampling Team are:

- Team Leader (directs the team);

- Sampling Technician(s) (responsible for collect/transport samples);

- Communications Technician (responsible for recording all important information concerning the sample and sample collection process, use communication systems, operate a video camera);

- Transportation Technician (responsible for movement of sampling personnel, equipment, and samples).

The Specialist Sampling Team must be well-trained and be involved in systematic basicand specialized training (basic training needed: Specialist CBRN Unit training; Chemical and Biological Occupational Protection, Emergency Procedures and Personal Protection; specific training needed: Environmental Sampling Techniques; Sample management, Shipping Procedures).

Training of personnel responsible for sample collection, handling, and analysis is important to providing the reliability of results from sample analysis. Consequently, proper training in sampling methods, handling of biological samples, and understanding of the effects of biological and environmental factors on analytical results should be a permanent and repeatable element of specialist training.

Additional Specialists will be needed to carry out specific SIBCRA missions. The standard team may be supplemented with different specialists, for example: forensic specialist (trained in proper crime scene investigations and particularly for forensic SIBCRA missions), medical specialist (for all issues involving biomedical sampling), CBRN technology specialists (for specific knowledge of agent production facilities), EOD specialists (Explosive Ordnance Disposal). A specialist may be required to distinguish agent production from other 'dual use' applications. Such extended teams are called to as Scientific Advisor Sampling Team/Scientific Advisor Forensic Sampling Team for a team increased with a forensic specialist. 


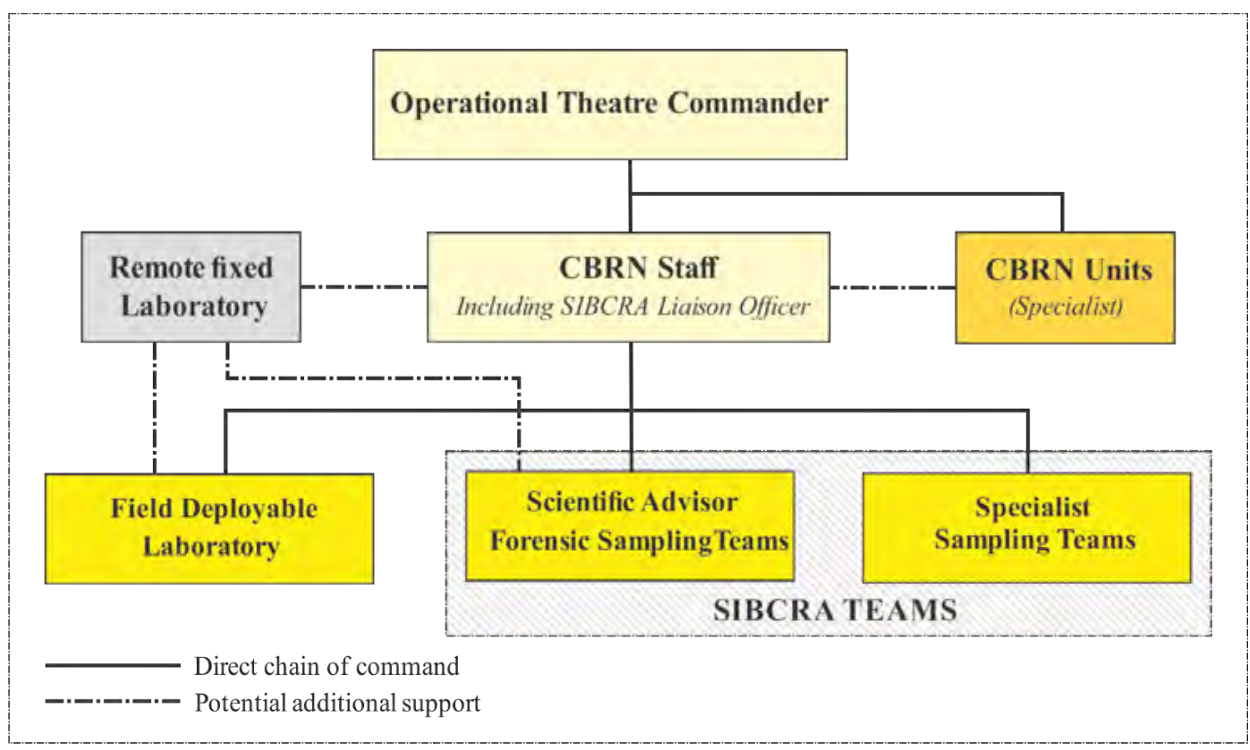

Figure 2. Suggested operational structure for SIBCRA missions

The Forensic Sampling Teams must be qualified to collect different types of samples required for an investigation. Scientific advisors can be both civilian and military personnel and they should have considerable expertise. It is expected that the Scientific Advisor staff will have in-depth knowledge of SIBCRA procedures and national or international forensic procedures. Scientific advisors can be employed in sampling teams or can be recruited as an external expert to manage SIBCRA missions. Scientific Advisor expertise should be involved in the risk analysis and selection appropriate protection equipment.

A very important step in the SIBCRA mission is decontamination. It is carried out by the sampling team (at the sampling site to prevent contamination of the material being collected, to avoid cross-reactions) and after leaving the sampling zone by a specialized Decontamination Team. Decontamination is carried out to reduce contamination on personnel, equipment, materiel and working areas. The primary aim of decontamination is restoring normal operational tempo during the SIBCRA mission. It is required that sample containers must be decontaminated before they leave the contaminated zone. Decontamination Team is responsible for decontamination of sampling personnel, material and equipment of all components the whole NBC contamination. In order to properly perform their tasks, the 'decon' team should be provided with appropriate decontamination equipment, for example: specialized decontamination chamber.

Sampling equipment necessary to conduct SIBCRA missions includes different supplies and instruments and depends on the nature of the threat and 
type of sampling methods (air sampling, liquid sampling, solid sampling, surface sampling, biomedical sampling). The SOPs should list the equipment necessary for sampling and instruct personnel on proper use of the instruments.

Equipment used during sampling operation:

- Equipment common to all sampling/surveying: supplies, personal protective equipment, communication/location equipment, supporting documentation, samples transportation;

- General sampling equipment and supplies: general sampling tools, specific sampling equipment and supplies, container related supplies;

- Specific biological sampling equipment.

All samples should be collected and handled using clean sampling instruments (recommended single-used materials). For biological agents sterilised equipment is necessary to avoid sources of contamination and samples containers should be inert to avoid absorption or reaction with collected samples. All material should be inspected periodically to assure it is in good condition and will function as expected. Sufficient numbers of spare sampling tools should be maintained in the event that some equipment breaks or becomes contaminated during sampling. Larger equipment or electronic instruments should be protected from contamination by plastic or other protective container.

Commanders must be aware of the risks their forces take in performance of sampling mission. Similarly, sampling personnel must be responsible for their own protection in a contaminated environment. In this reason is required that the SIBCRA Team was equipped with Individual Protective Equipment (required, recommended, optional equipment). The basic protective equipment for most scenarios consists of respirators, disposable garments, hand and foot protection and other items which comprise the individual protective ensemble.

\subsection{Sampling strategies for $C B R N$ incidents}

Sampling process is the first key element of a CBRN incident investigation (Fig. 3). Correct sampling of representative samples is very important to further operational and political action.

The aim of the sampling process is gaining of the representatives samples of material to the laboratory analysis to detect of the used biological agent and to defined of the scale of the contaminated area. To warrant the correct sampling process (considered choice of representative samples, no cross-contamination, viability, safety etc.) it should be conducted by trained personnel with specific equipment. In CBRN incident investigation are two types of sampling process: field and forensic sampling.

Field sampling is designed to allow the commander to making early operational decisions about further operational activities of various services 
(emergency, medical, decontamination) in the field, as well as the selection of appropriate protective equipment (protective clothing, respiratory protection etc.). The samples are usually collected by the sampling team in the primary composition.

Forensic sampling is performed for strategical and/ or political/ military purposes. The samples have to be collected by the sampling team extended by additional specialists (investigator, forensic expert, medical expert, epidemiologist, CBRN specialist), and the samples are used to confirm the unambiguous use of the CBRN agents by the opponent. Sample analysis is performed using the advanced diagnostic techniques in the reference laboratory to ensure that the result is undeniable. The design of sampling strategies for CBRN incidents needs to provide to sampling team the key information (sample types, size and numbers, places where the samples should be collected, needs equipment) to correct perform the sampling event. The design should be objective in nature, technically defensible, and practical to implement. A well designed strategy is needed to obtain the maximum amount of information from the number of samples.

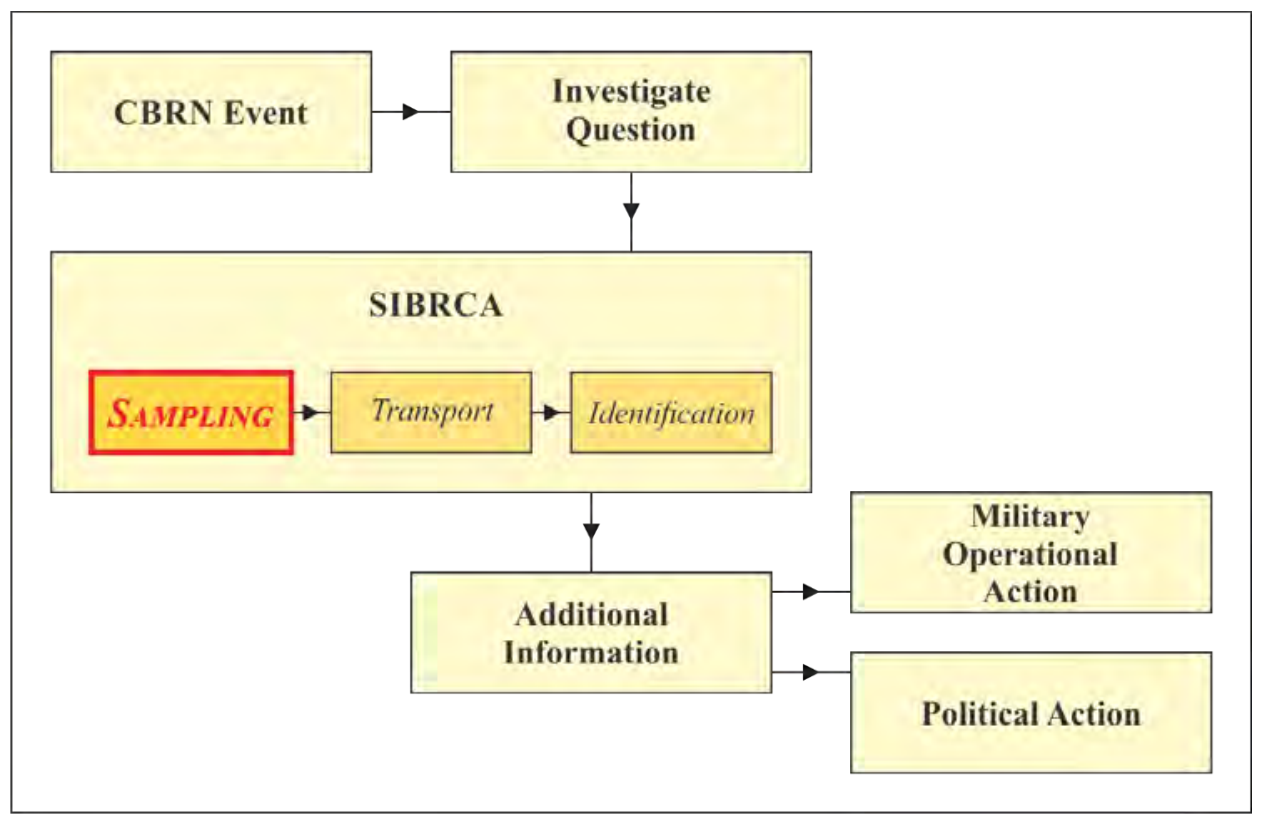

Figure 3. Position of the sampling process in the SIBCRA missions in the CBRN event-response chain

Designation of the sampling process can be delineated for three separate goals: identification, determination of intensity, or confirmation.

Accomplishing each of these goals is possible through the using of different sampling strategies: 
- Judgmental for identification purposes;

- Systematic for determining the intensity;

- Random for confirmation purposes.

For sometypes of operations (CBRN orcriminal investigation, environmental repair) it is possible to use a combination of these strategies.

Judgmental Sampling. In judgmental sampling, only a small numbers of samples are collected and sampling is directed toward a specific incident where the probability of finding the contaminated material is very high. The advantages of the judgmental strategy of sampling that it operational cost is less, than other strategies. However in interpretation of the results of analysis the high care level have to be taken, because the valid of the data is dependent on intelligence activities and knowledge about the site.

Judgemental sampling can be useful to:

- Provide information on which agent or agents were used in a particular CBRN incident;

- Confirm the presence or level of contamination in a specific location (e.g. 'the worst' location);

- Provide the information needed to identify the next operational phases.

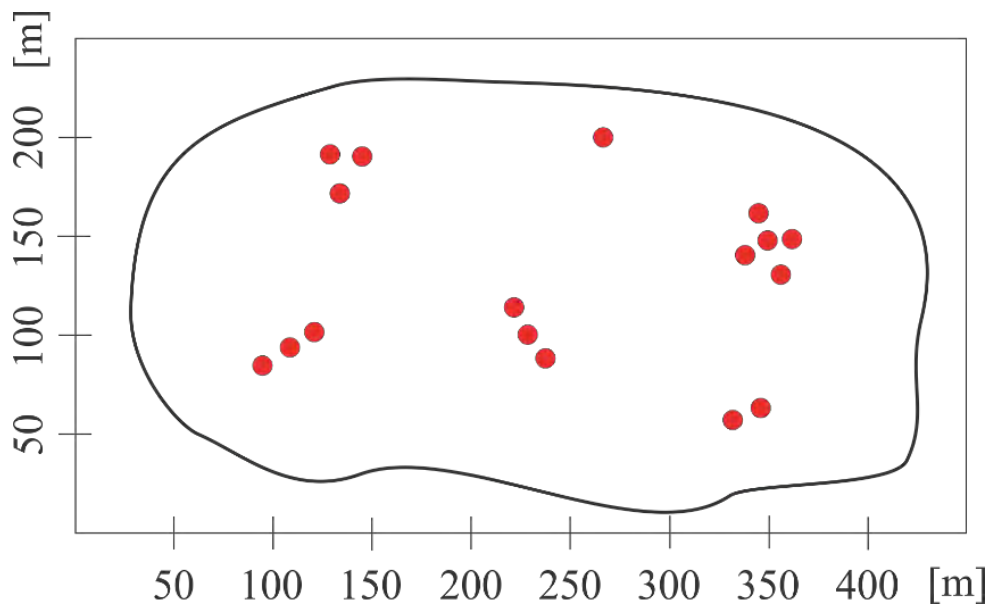

Figure 4. Judgmental Sampling Strategy

Systematic Sampling. Systematic sampling is much less biased than previous sampling strategy. To ensure complete coverage of the area, a grid model is used where the samples are collected in the intersection of the grid lines. This type of strategy helps in defining the level of contamination in different places and boundary of contamination but needed larger numbers of samples. 
Systematic sampling can be useful to:

- Shows gradient of contamination of area (help created the border between hot and warm zone in CBRN incident);

- Criminal/ CBRN investigation, decontamination preparations.

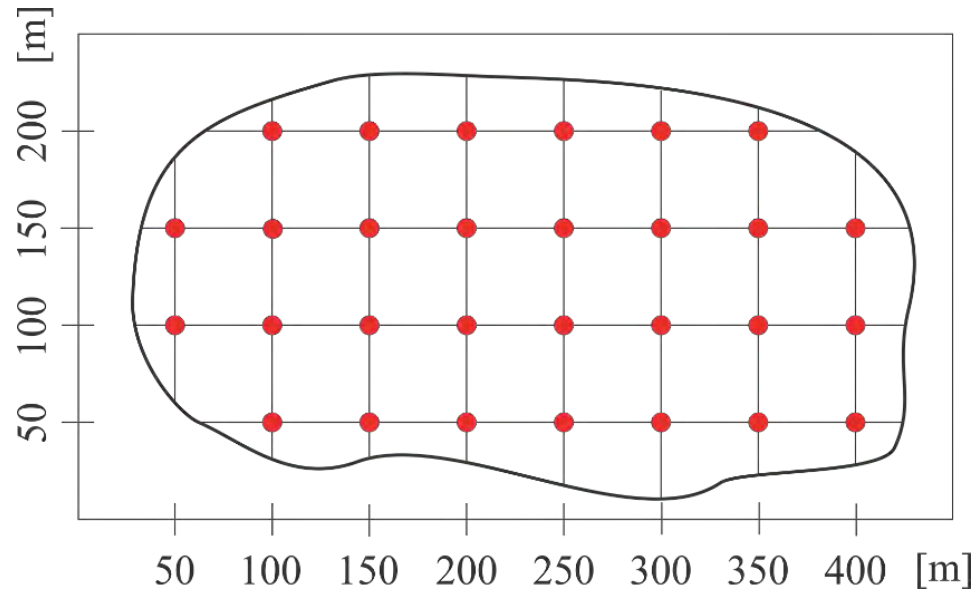

Figure 5. Systematic Sampling Strategy

Random Sampling. Random or unsystematic strategy of sampling may be very useful when the specific contaminated area is no known or when there is concern, but a lack of definitive information to selection a specific sampling zone. It requires a very large number of samples. This strategy of sampling is also known as a surety operation, assists in determining whether a threat remains in the location, e.g. after decontamination process.

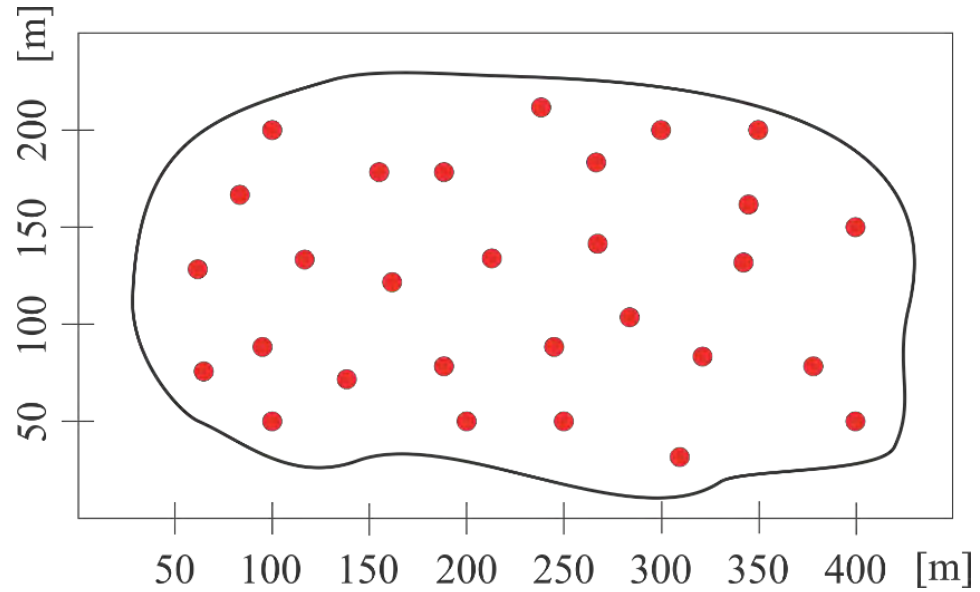

Figure 6. Random Sampling Strategy 
During development of the strategy and selection of the sampling methods to be used, the following elements must be considered: legal regulations; available intelligence (risk analysis, type of CBRN incident, activity of military and/or paramilitary organisations, the epidemiological situation etc.); existing equipment; required size and number of samples; the diagnostics capacity of field and/or reference laboratories (available procedures and analytical equipment), and costs.

\subsection{Phases in the process of biological sampling}

Biological sampling process (as well as other CBRN factors) have the following phases:

- Immediate Phase Operation;

- Urgent Phase Operation;

- Late Phase Operation.

The task of the first phase (Immediate Phase Operation) should be made as soon as possible (within the first minutes after the incident to several hours maximum). Commanders must prepare a model decision tree CBRN operations which include force protection, the management of casualties and confirmation of the hazard. The success of the operation depends on the use of airborne and surface detectors (including CBRNs), as well as having regard the following vectors:

- Mission (establish level and type of threat);

- Enemy (adequate protection of the personnel);

- Terrain and weather (impact on the spread of hazardous material);

- Military (support of specialized military forces);

- Time (to be effective, protective actions must be implemented as soon as possible post incident. This requires an intensive and sustained effort of surveying and sampling, particularly during the first minutes to hours post event).

The listed factors are included in the first steps of model post-incident decision tree (Fig. 7) and should be prepared by the SIBCRA Team (Flow Chart Actions).

Where the information provided by the intelligence reports the high risk of CBRN agents, it is necessary to notify, consult or deploy specialized groups. Deployment of these groups is also indispensable if the threat is detected by the reconnaissance and monitoring forces. When a threat is detected, you should adopt a protective attitude and employ detection by using personal security and detection measures. It is also important to generate and send a report of the incident to the higher headquarters. If the incident is the result of criminal, terrorist or enemy activity, the higher headquarters may request the deployment of additional forensic sampling teams. 


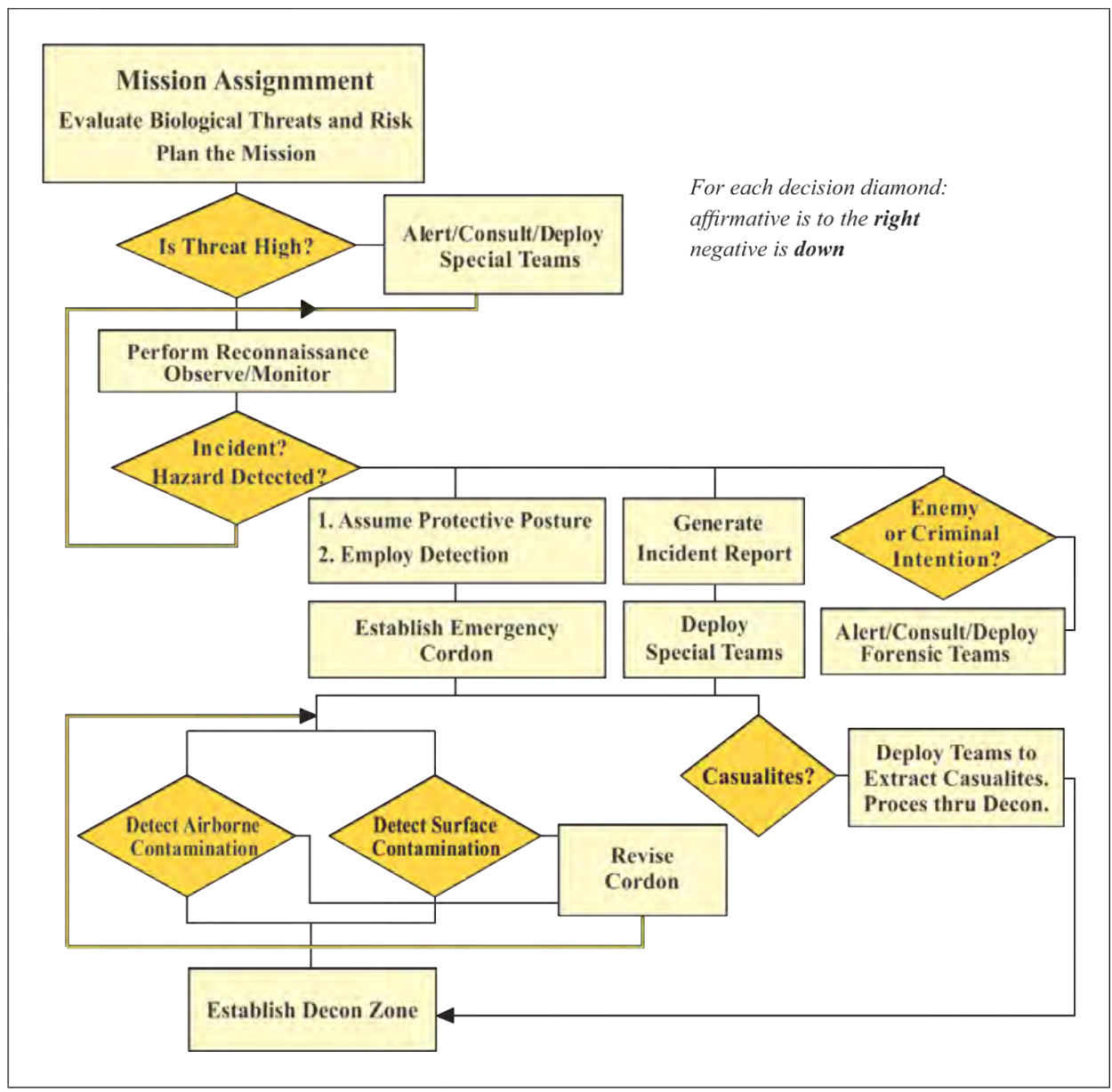

Figure 7. Immediate Phase Operation

Next to, and with the information from the monitoring and protection activities the Emergency Cordon is created (minimum 100 meters up to several kilometres depending on the incident size and expected hazard area). The revise of Emergency Cordon is the result of continuous monitoring hazard area (SIBCRA Team task) and have simultaneously affects to the location of the decontamination zone. Contamination control area (CCA) should be established in the upwind warm zone border with the cordon area. If there are also causalities, they should be secured by appropriately trained medical personnel.

The purpose of Urgent Phase Operations is to allow military and political authorities to initiate effective protective actions and countermeasures in order 
to prevent further direct exposure, ingestion, inhalation, and dispersion of contamination, and to begin the process of site recovery (Fig. 8).

SIBCRA Team in this phase should:

- Air sampling (assessing airborne contamination);

- Soil or road dust sampling (assess environmental contamination level);

- Field identification (in situ analysis via portable instruments, via deployed laboratory, preliminary data from immunochemical hand-held test kits);

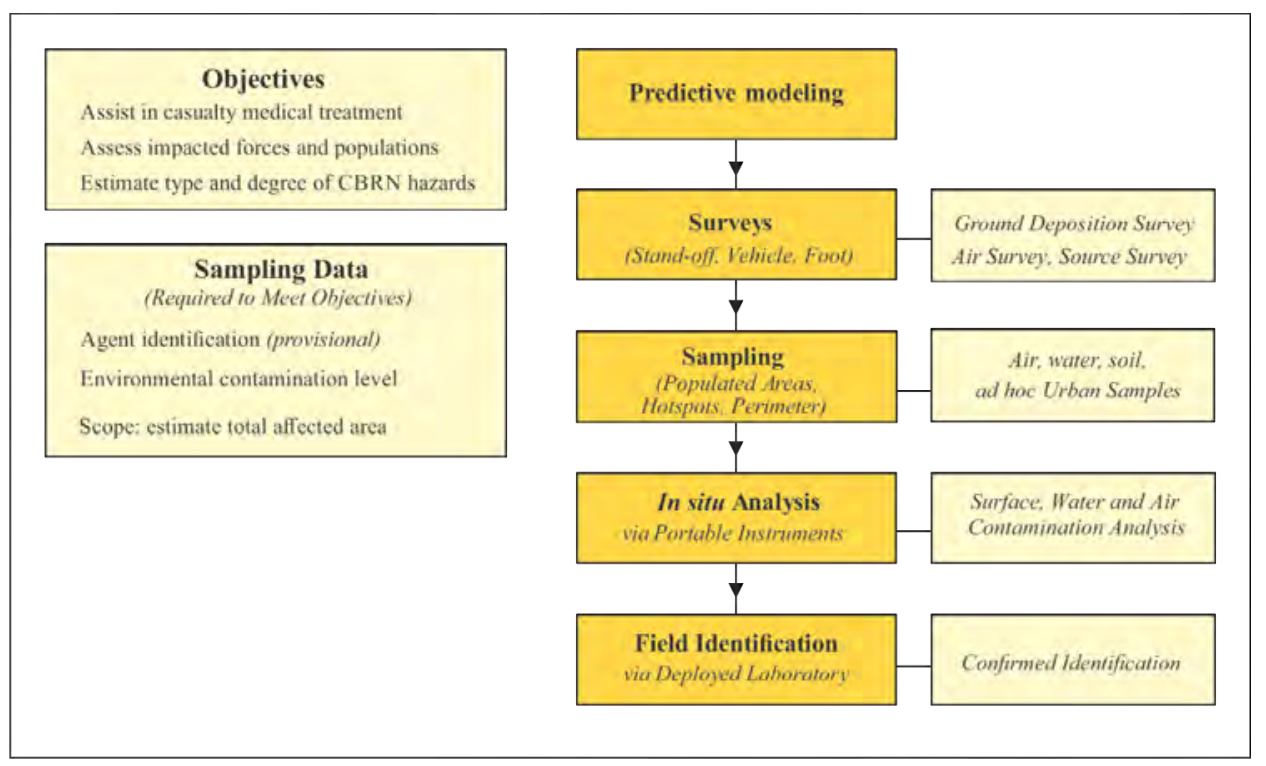

Figure 8. Urgent Phase Operation

The third Late Phase Operations (Fig. 9) require monitoring contamination levels for the protection of local populations and deployed forces from direct exposures, ingestion of contaminated materials, and inhalation of re-suspended material. Current research include determining the location and degree of the environmental contamination and comparing the result with the exposure limits.

Types of samples:

- Soil/ urban sampling;

- Water, milk, and other foodstuffs originating from contaminated areas;

- Bioassay samples (to support post-exposure assessment);

- Quality control samples to support accuracy and precision of laboratory measurements;

This activity is likely to occur days to potentially months following the incident. 


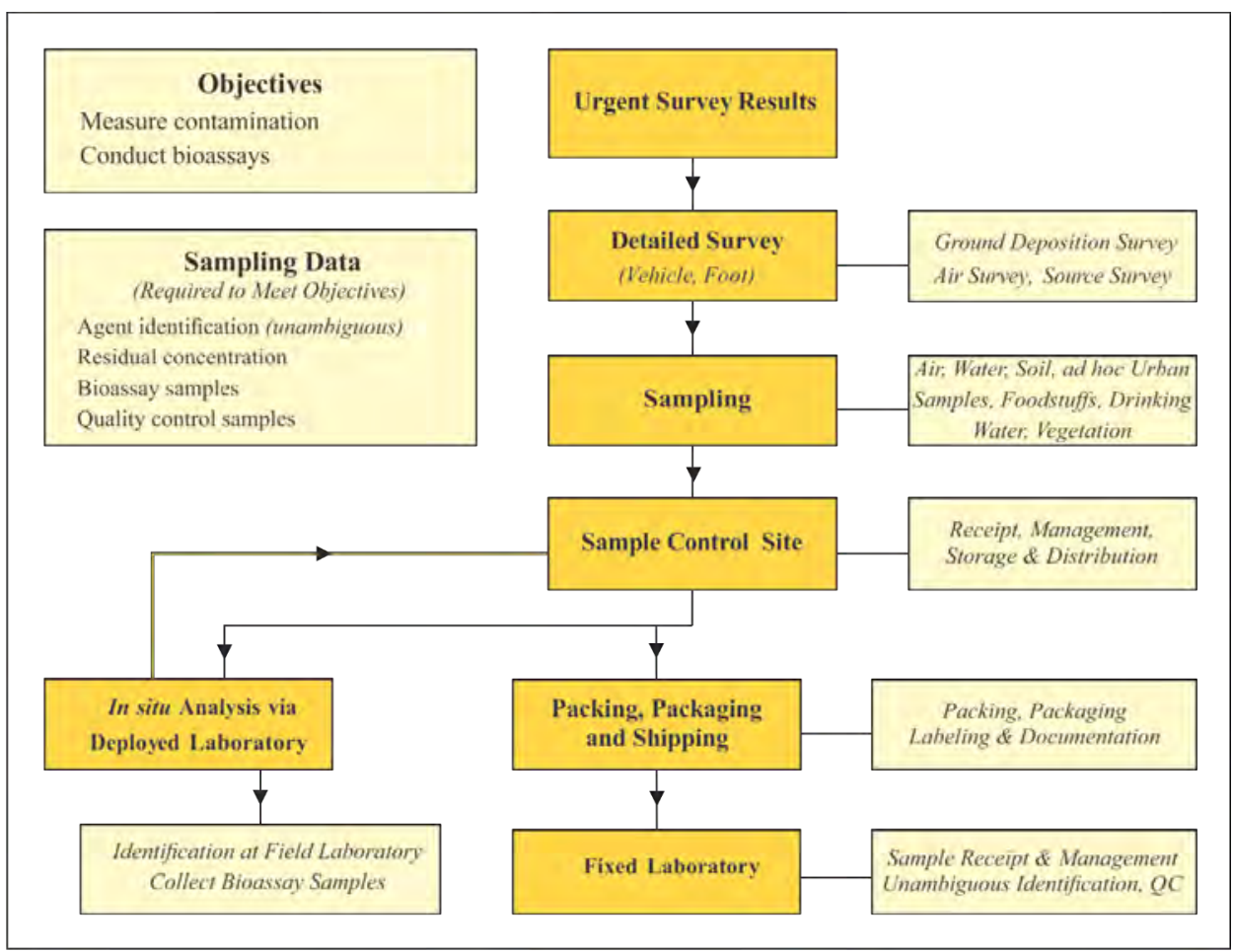

Figure 9. Late Phase Operations

\subsection{Documenting the sampling process}

Each sample can be identified if it is written on or affixed to the sample container. The safest and simplest way to label a sample is writing on the sample container. The other method of labelling samples is to use tags or adhesive labels which should be affixed immediately after placing the sample in container. In addition to resistance to external factors (e.g. degradation, fading, temperature) labelling should no contaminate the sample. The sample number or ID should be clearly described on the sample and additional sample data sheet. Further the label should contain as much information as possible. Individual sample identifier can be a combination of site location and time. The following method is recommended: ALATLOGDDTTTZMMMYYYYXX. 
These tags are described in the table below:

Table 1. Sample ID tags

\begin{tabular}{|c|c|c|}
\hline Designation & Specification & Examples \\
\hline A & Media description & $\begin{array}{l}\text { A - Air } \\
\text { S - Soil } \\
\text { H - Hydrological samples (Water and } \\
\text { Snow) } \\
\text { V - Vegetation } \\
\text { D - Dairy (Milk) } \\
\text { G - Grain } \\
\text { M - Meat } \\
\text { O - Other Foodstuffs } \\
\text { U - Urine } \\
\text { F - Faeces } \\
\text { W - Wipes (Smears and Swipes) } \\
\end{array}$ \\
\hline LATLOG & $\begin{array}{l}6 \text { digit latitude-longitude GPS } \\
\text { or other geographic coordinate } \\
\text { system (np. UTM) }\end{array}$ & $\begin{array}{l}514155021974-51^{\circ} 24^{\prime} 56^{\prime \prime} \mathrm{N} 21^{\circ} \\
58^{\prime} 29^{\prime} \mathrm{E} \\
\text { 34N } 5677825696489 \text { - UTM }\end{array}$ \\
\hline $\mathrm{DD}$ & Day of the month & 05 \\
\hline ТТТ & Time (24 hours system) & 1654 \\
\hline $\mathrm{Z}$ & Time zone & $\begin{array}{l}\text { A-alpha } \\
\text { Z-Zulu time }\end{array}$ \\
\hline MMM & $\begin{array}{l}\text { Alphabetically abbreviated } \\
\text { month }\end{array}$ & $\begin{array}{l}\text { AUG - August } \\
\text { JUN - June }\end{array}$ \\
\hline YYYY & Year & 2017 \\
\hline XX & $\begin{array}{l}\text { Sequential number (identify } \\
\text { field duplicate or split samples, } \\
\text { or sampling method) }\end{array}$ & 02 - second field sample \\
\hline
\end{tabular}

Each sample for analysis must have accompany sample data sheet containing the following critical information:

- Data sheet general code number;

- Specific identification number of sample;

- Sample distinction, field blank and duplicate;

- Operation (or incident) identification;

- Date and time of operation (incident);

- Grid and GPS sampling location;

- Sample site description (may refer to photographs or video);

- Casualties symptoms; 
- Sampled Medium;

- Method of sampling and used equipment;

- Preparation and preservation of sample;

- Name (or ID) of person (sampling team) collecting the sample;

- Physical and meteorological condition (at sampling time);

- Special handling, temporary storage or safety precautions;

- Result of field expedient assays using hand-held instruments;

- Signatures.

Examples of all data sheets for CBRN agents are included in Appendix C of AEP-66. The example sheets used for biological agents are shown below. 


\section{BIOLOGICAL ENVIRONMENTAL SAMPLE}

\section{SAMPLE NUMBER:}

Team Leader:

Location ID:

GPS Coordinates:

Time and date (global):

Longitude

Location Description:

(Addres if applicable)

Weather Conditions:

Field Observations:

Sample Type

Normal sample
QC: $\square$ Duplicate
QC: $\square$ Background

$\square$ Co-located

Control sample

Field blank

Sample Media

$\begin{array}{ll}\square \text { Swipe } & \square \text { Biota (specify) } \\ \square \text { Soil } & \square \text { Gutter dirt } \\ \square \text { Sediment } & \square \text { Surface water (specify) } \\ \square \text { Vegetation } & \square \text { Roan / surface dust } \\ \square \text { Precipitation } & \square \text { Ad hoc }\end{array}$

Sample Description

e.g. type of soil, quantity (volume or mass),

sampled area and depth

Sample Tool - Area:

Sampling method

Figure 10. Biological Environmental Sample Form 


\section{BIOLOGICAL FOODSTUFF SAMPLE}

\section{SAMPLE NUMBER:}

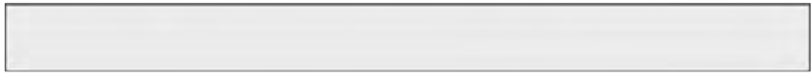

Team Leader:

Location ID:

GPS Coordinates:

Time and date (global):

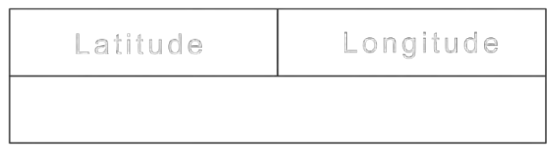

Location Description:

(Addres if applicable)

\section{General Foodstuffs}

Location of acquired sample in production line

Source location of raw product

Distribution points for foodstuffs

Reason for Sampling:

Milk Specific

Cow

Goat

Other:

Location of acquired sample in production line

Source location of raw product

Distribution points of milk:

Farm where cows originated:

Feed Type:

Pasture

Stored Feed

Other:

Grazing Location:

Sample Description

e.g. type of soil, quantity (volume or mass), sampled area and depth

Figure 11. Biological Foodstuff Samples Form 


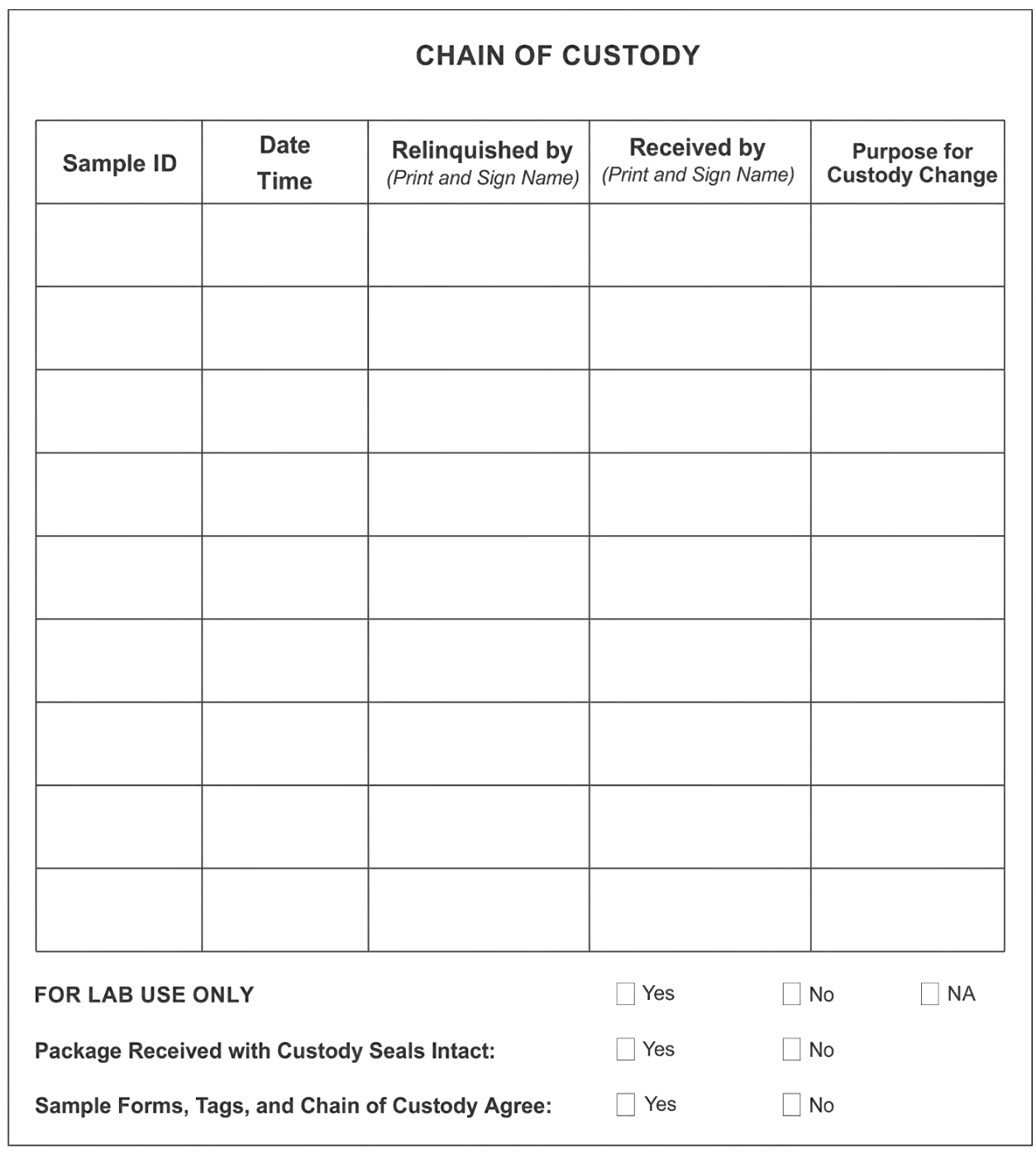

Figure 12. Chain of custody Form 


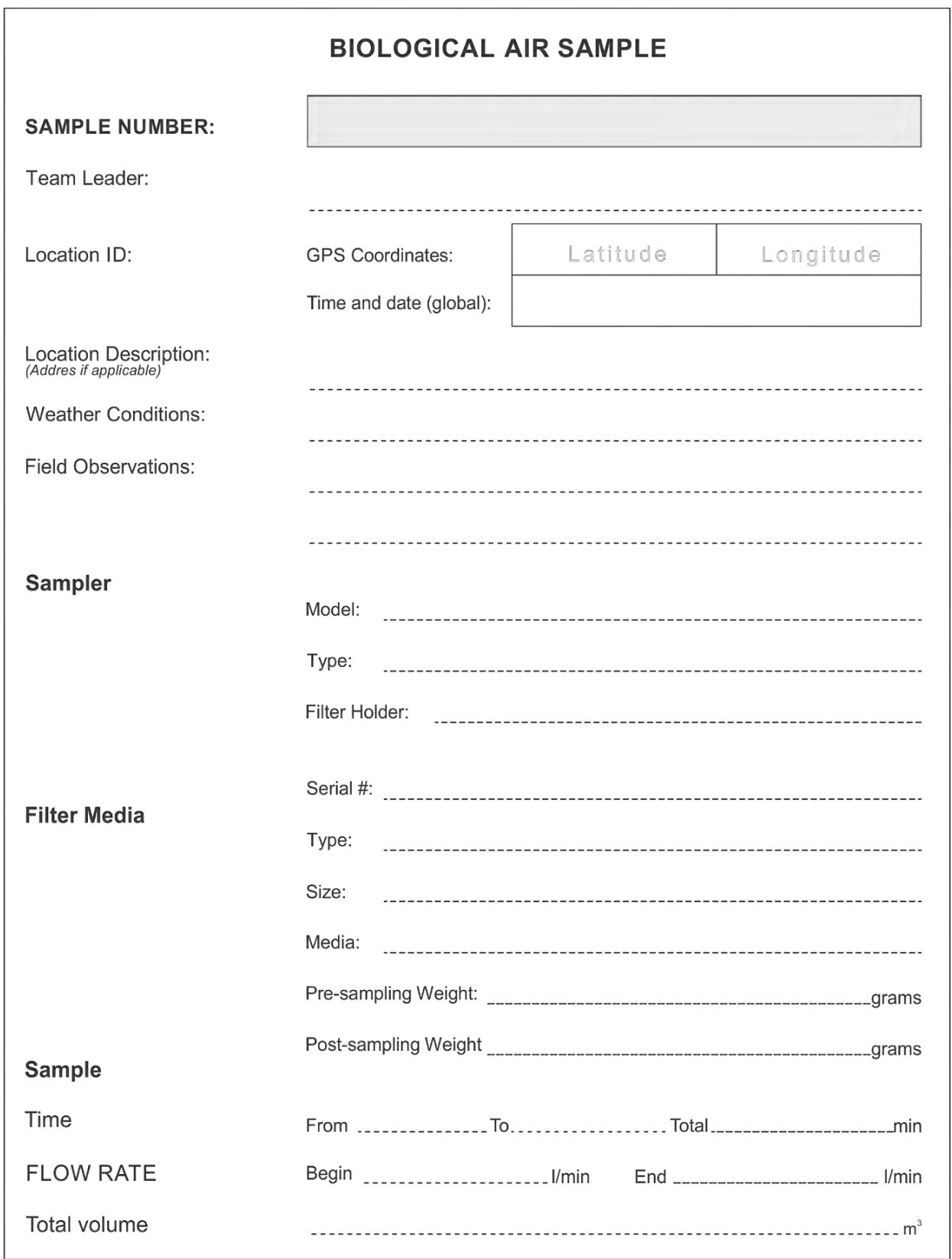

Figure 13. Biological Air Sample Form 


\section{BIOLOGICAL BIOASSAY SAMPLE}

\section{SAMPLE NUMBER:}

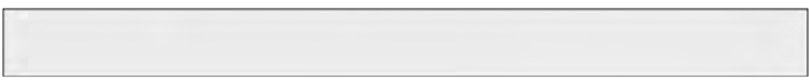

Team Leader:

Location ID:

GPS Coordinates:

Time and date (global):

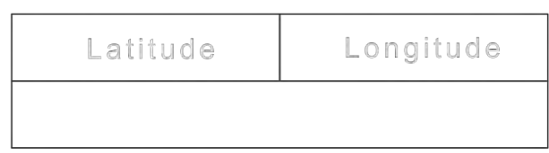

Location Description:

(Addres if applicable)

Weather Conditions:

Field Observations:

\section{PATIENT}

Last Name:

First name:

ID Number

UNIT

Address

SEX

\section{Sample}

Type

Quantity

Figure 14. Biological Bioassay Sample Form C-9

\section{References}

AEP-10 NATO Handbook for Sampling and Identification of Biological, Chemical and Radiological Agents (SIBCRA).

AEP-66 NATO Handbook for Sampling and Identification of Biological, Chemical and Radiological Agents (SIBCRA). 
ATP-3.8.1 Specialist CBRN Defence Capabilities.

AJP-3.8 (STANAG 2451), Allied Joint Doctrine for NBC Defence.

Biological Incident Response \& Environmental Sampling - a European Guideline on Principles of Field Investigation.

Contaminated Land Management Guidelines No. 5. Site Investigation and Analysis of Soils (Revised 2011).

EPA QA G-5S, Guidance on Choosing a Sampling Design for Environmental Data Collection for Use in Developing a Quality Assurance Project Plan.

Guide for the Selection of Biological Agent Detection Equipment for Emergency First Responders, Preparedness Directorate Office of Grants and Training 2nd edition.

JP 3-11, Joint Publication 3-11, Operations in Chemical, Biological, Radiological, and Nuclear Environments, 04 October 2013.

MTTP NBC Protection, Multiservice tactics, techniques, and procedures for nuclear, biological, and chemical (NBC) protection. June 2003. ASIN: B0041BLO0E.

Soil sampling for environmental contaminants IAEA-TECDOC-1415. 